\title{
Competing explanations for adopting energy innovations for new office buildings th
}

\author{
Walter J.V. Vermeulen*, Jeroen Hovens \\ Copernicus Institute for Sustainable Development and Innovation, Utrecht University, Heidelberglaan 2, P. O. Box 80115, 3508 TC Utrecht, Netherlands
}

Available online 2 June 2005

\begin{abstract}
An integrative model to explain potential adopters' decisions to adopt energy innovations was adapted and applied in the field of new office building construction. We tested the relative effects of competing theoretical explanations (derived from economics, innovation science and policy science) on the decision to adopt. The research covered 35 projects representing $9 \%$ of the total volume of new office construction in the Netherlands between 2000 and mid-2002. Two levels of explanations for adopting innovations were derived: (a) the potential adopter's weighed assessments of the innovations and his or her nature of decision making and (b) explanation of those first-level variables. Using multiple regression techniques, we determined the relative influence on innovation-adoption of variables covering economy and technology, government intervention, company characteristics, and influences from market and society. The decision to adopt 'mature' innovations, in contrast to 'young' innovations, is based more on routine procedures than project-specific considerations. Policies need to take this difference into consideration. We also show evidence that in promoting adoption of E-innovations for new office buildings the Dutch system of applying Energy Performance Standards and subsidies proofs to be effective.
\end{abstract}

(C) 2005 Elsevier Ltd. All rights reserved.

Keywords: Policy instruments; Diffusion; Sustainable building

\section{Introduction}

Many European countries have strong traditions of stimulating sustainable construction, including promotion of new energy saving technologies. Both national and local authorities have supported pilot projects of sustainable housing, encouraging the use of innovations such as high-efficiency condensing boilers, solar domestic hot water systems, photovoltaic (PV) cells, heat pumps and combined heat and power.

In the Netherlands, the central government has successfully introduced energy performance standards in building regulations, financial incentives, and volun-

\footnotetext{
${ }^{4}$ See for more information www.copernicus.uu.nl/esp: look at 'staff'; 'Vermeulen'.

${ }^{*}$ Corresponding author. Tel.: + 3031 2532989; fax: + 30312532746.

E-mail address: w.vermeulen@geo.uu.nl (W.J.V. Vermeulen).
}

tary agreements with the building and construction industries (Haarman et al., 2000). Extensive checklists of possible techniques and designs are available, such as the national packages for sustainable building (Anink et al., 1996). Local energy-efficiency policies support and often extend national policies (Waals et al., 2000; Waals and Vermeulen, 2000). As a result, by 1998, 32\% of all new building permits met a specified minimum standard for sustainable building, the so-called 'yardstick' (Novem, 1999).

Although this may appear to be quite an achievement, a European comparison reveals the Netherlands to be somewhere in mid-field in terms of environmental innovations (Hal and Hulski, 1999). Yet, the energy performance standard, introduced for various types of buildings in 1995, is assumed to play a major role in the increased adoption of sustainable building and new sustainable energy technologies. It serves as an example 
for the current implementation of the EU Energy Performance Building Directive. ${ }^{1}$

The Dutch Energy Performance Standards (EPS) are specified for various types of buildings and have been sharpened several times since their introduction. The EPS is a flexible regulative instrument that includes a method to calculate the energy performance of a large number of possible technical measures. At the same time, it gives the designer freedom of choice. Possible measures included in de EPS for utility buildings, like offices, are the choice of wall insulation, type and size of windows, ventilation, heating and cooling, ventilators, solar hot water systems, lighting and PV cells. However, some possible energy reducing measures are not included, like choices in the type of elevators and kitchen equipment.

The introduction of EPS was not the only policy change, nor the only influencing factor, in the field of sustainable construction. Therefore, its effectiveness, relative to those other policies and influencing factors, in promoting adoption of sustainable building and new sustainable energy technologies is not clear. The other policies include subsidies, covenants, and information and assistance strategies. And factors, such as supplier and consumer demands, have also influenced increases in sustainable building and energy technologies. To aid policy makers in strategically designing or altering policies, we investigated these unknowns. For practical reasons, we limited our study to a specific area of sustainable construction, office buildings.

The diffusion of sustainable technological innovations throughout society is dependent upon actors who adopt those innovations. An actor's decision to adopt a technology is, in turn, dependent upon the variables that influence his or her decision-making process. Specifically, by 'potential adopters' we mean those persons in a decision-making position in a project development organization who decide what technological innovations to incorporate in the construction of a new office building. To focus on the variables influencing their decisions, our central research question was:

To what degree and in what relative proportions do variables representing the nature of decision-making, company characteristics, technology characteristics, economic characteristics, government policy, and influences from market and society explain potential adopters' decisions to adopt E-innovations in new office building construction?

To answer this question, we adapted a previously developed conceptual model to the specific area of new office building construction. We applied this model to four areas of technological innovation that directly affect the energy performance of office buildings. Data

\footnotetext{
${ }^{1}$ EU Directive 2002/91/EU, 16-12-2002.
}

were gathered through interviews with the potential adopters, as well as from other sources. We analyzed the data to determine the relative effects of two main explaining factors of adoption: (1) the potential adopter's own assessment of the value of the innovation and (2) the nature of decision making in the potential adopter's organization. In a second level of analysis, we explained each of these main factors in specific terms of company characteristics, technology characteristics, economic characteristics, government policy, and influences from market and society.

Many of these specific explanations can be influenced by policies and, in that light, we discuss the consequences of our results to policy-making and the relative effectiveness of existing policy instruments that address energy-reduction innovations in new office buildings (Vermeulen et al., 2004). ${ }^{2}$

\section{The decision-making process of the potential adopting actor: an inductive integrative model}

Research into the diffusion of environmental innovations often tends to focus on the feasibility of one particular technology. Few try to explain how technology spreads throughout society. Moreover, little attention has been devoted to integrating available knowledge about innovation and diffusion from such disciplines as policy science, economics, and innovation studies, or knowledge from specific fields of innovation such as energy in construction and various industrial applications.

In an earlier study, we integrated different partial explanations for the diffusion of energy-saving innovations in industry and the built environment into one conceptual framework (Dieperink et al., 2004). We based this integration on a secondary analysis of relatively well-elaborated studies dealing with the diffusion of heat pumps, combined heat and power, and condensing boilers, both in industry and the built environment. The core of our conceptual framework was the decision-making process of the potentially adopting actor. We concluded that the actor's characteristics and the networks in which the actor participates (government, market, and society) could have impact on his/her decision-making process. Furthermore, technological and economic characteristics of the innovation and more general contextual factors also influence the actor's decision-making process.

Our secondary analysis of those empirical studies led us to identify a broad range of explanations that we interpret as inputs in the decision-making process. This,

\footnotetext{
${ }^{2}$ This research project was commissioned by SenterNovem, Utrecht, see www.novem.nl
} 


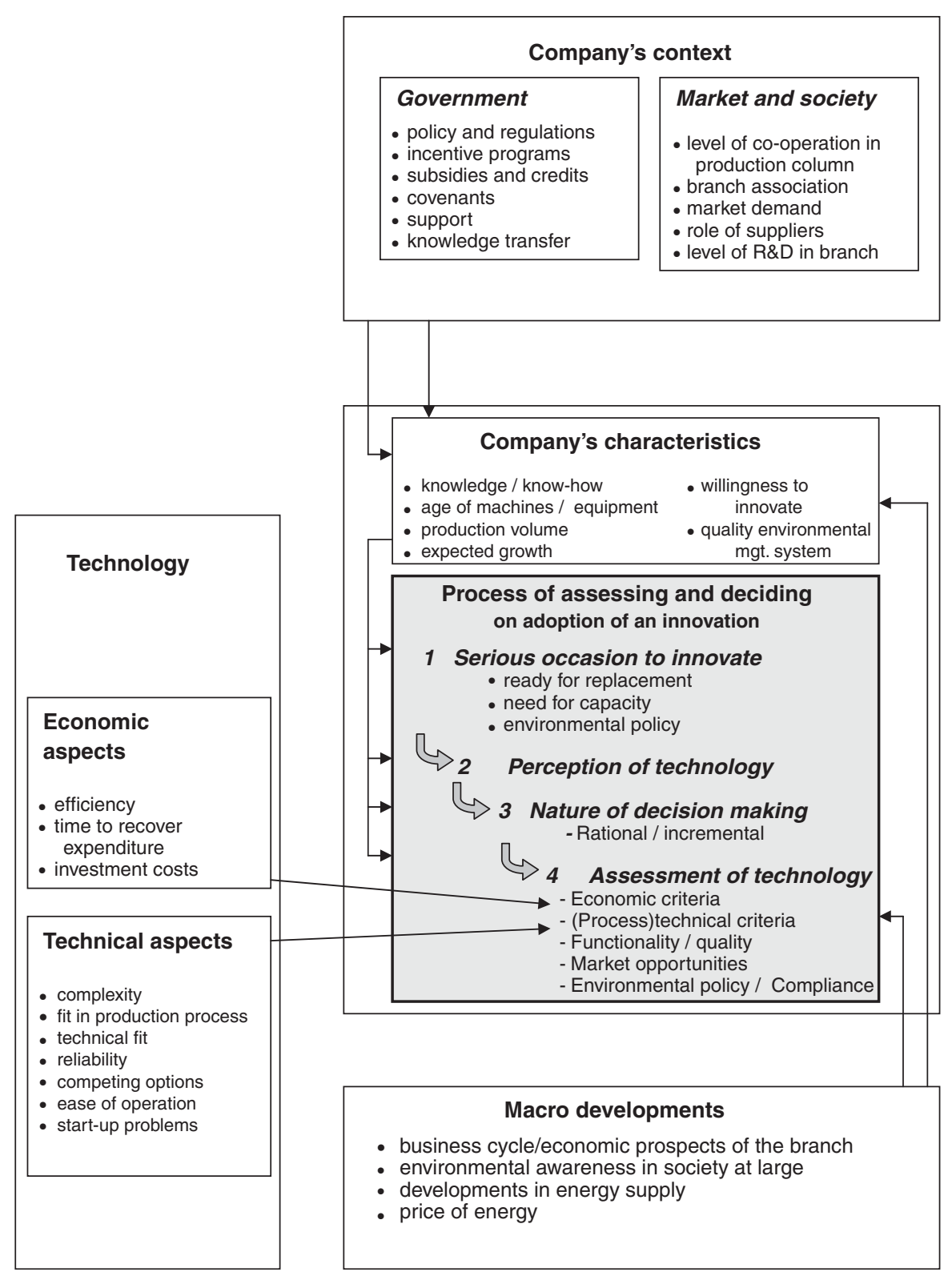

Fig. 1. Integrative framework explaining diffusion of innovations.

in turn, led us to form the research framework as shown in Fig. 1.

Essentially, the framework places the decision-making process (the occasion, the assessment, its comprehensiveness, and the weighing of various criteria) of the potential adopters of innovations at the core and embeds it in corporate characteristics (in the case of a company). The variables referring to the context of the adopter (both the socio-economic and the policy setting), the technical and economic characteristics of the innovation, and the characteristics of the macrocontext have an indirect effect. They operate in various ways through the decision making of potential users.

A firm's decision making about possible innovations is not an automatic consequence of favorable techno- economic features of an innovation. Neither is its decision making an automatic consequence of coercive or strong stimulating policy activities. A firm's assessments of newly available innovations are to be seen as the final step in a four-step decision-making process. In order to consider a new technology at all, a company will need a serious occasion that distracts attention from its core business and routines (step 1). In addition, a non-constraining initial perception of the reliability and technical fit of the innovation will be needed (step 2). Then the nature of decision-making procedures, mainly influenced by the firm's procedural culture and organization, etc., will determine the thoroughness of the assessment (step 3). In economic analyses, the firm's decision-making procedures are often implicitly 
presupposed to be of rational-synoptic nature. In practice, however, the effort given to such analyses, the perceivable assessment criteria that are actually applied and values they are given, are not rationally determined (step 4).

Taking this combination of 'companies characteristics' and 'decision-making features' as the core of the model, enables us to illustrate how other explanatory variables affect actual adoption. For instance, returnon-investment can be analyzed objectively as a feature of a specific innovation. But to give an explanation for adoption, we need to know how the company dealt with this assessment criterion and, indeed, whether they applied this criterion at all. Then we need to know how this criterion was compared with other criteria. If it was applied, the company might abstain from the investment because of a relatively low return on investment. Another example of how other explanatory variables affect actual adoption is the 'technical fit' of a technology. Although a technology may be judged to be widely applicable, to be an explanation for (non)adoption we need to know if the company found the innovation to be applicable in their situation. Here, company characteristics, like the age of their existing equipment or willingness to innovate, may intervene.

Using this conceptual model for empirical research, we made it operational in a second model expressing theoretically derived causally related variables. Here again, the decision process forms the core of the model, taking two aspects as core variables: the nature of process and the contents of the decision making. This implies that all suggested explanations originating from outside the decision-making actor should somehow be linked to either the decision-making process or the decision content. Thus, we can reorganize the model as a scheme of coupled variables.

Theories on rational decision-making assume that calculating actors weigh diverse pros and cons of alternatives for action. This assumption of actorsmaking-rational-decisions is often reflected in policy advice and tools designed to help companies to make 'proper' decisions (Poel et al., 2002). Research on decision making in businesses, organizations and individuals have led to various perspectives that are being used side by side (Glasbergen, 1984; Hickson et al., 1986; Kickert, 1986; Hoppe, 1987). At one side, we see prescriptive rational theories, like the classic rational-synoptic model (Lindblom, 1959, 1968, 1977) ${ }^{3}$ and responses to it (Kickert, 1986; Korsten and Toonen, 1988). At the other side, we see descriptive theories, emphasizing the limited degree of purpose and rationality in common decision-making practices ('garbage

\footnotetext{
${ }^{3}$ When speaking of 'rational-synoptic decision-making' we mean decision-making based on a comprehensive analysis addressing all possible effects of the decision applying all relevant assessment criteria.
}

can process' March and Olsen; Glasbergen, 1984; Bekke, 1988). On the one hand, decision-making theory can be described as developing from normative to descriptive and, on the other hand, as developing from context free explanations towards context bound explanations.

We have taken a somewhat different approach. Our starting point is the fundamental assumption that both rational and social factors influence the decision making of an entrepreneur being addressed by policy makers. Furthermore, policies that support new sustainable innovations demand companies to diverge from common practices. However, a company must face a serious occasion before it will abandon its existing, practically proven routines. Moreover, to assume that companies, in response to such policies and such a serious occasion, will rationally make decisions and evaluate all available opportunities is not realistic. Acknowledging influences of various social actors on both the process and content of decisions captures the social dynamics. This implies that interpretations and judgements of decision makers can be the result of efforts of third parties to influence them.

To quantitize the analytical rational dynamics of decision making, we asked the actors to assess innovations based on various criteria and the relative weight of each criterion in making a decision. This enabled us to generate decision-specific scores for each respondent and to calculate a sum score.

The social dynamics of decision making imply that interpretations and judgements of decision makers can be influenced by third parties, who could be either policy makers or market actors. In our study we captured the social dynamics by analyzing the nature of decisionmaking processes. To measure the nature of the decision-making process, we developed a process variable. The variable is based on both the scientific literature and government publications advising construction companies about integrating design and development processes for office buildings (Novem, 2000a,b; Poel et al., 2002). This process variable includes 11 process aspects, expressing the rationalsynoptic decision making ideal:

(a) Right from the start of the projects, initial ideas on energy-use are communicated to all stakeholders.

(b) All possible measures contributing to a better energy performance are considered.

(c) In an early stage, opportunities and barriers for reducing energy-use at the specific location are studied (looking at combined heat and power; district heating, clustering, solar energy).

(d) All relevant actors (municipality, advisors, energy supplier) are involved from the start of the project.

(e) Possible choices for low energy or green energy appliances are thoroughly discussed with these actors. 


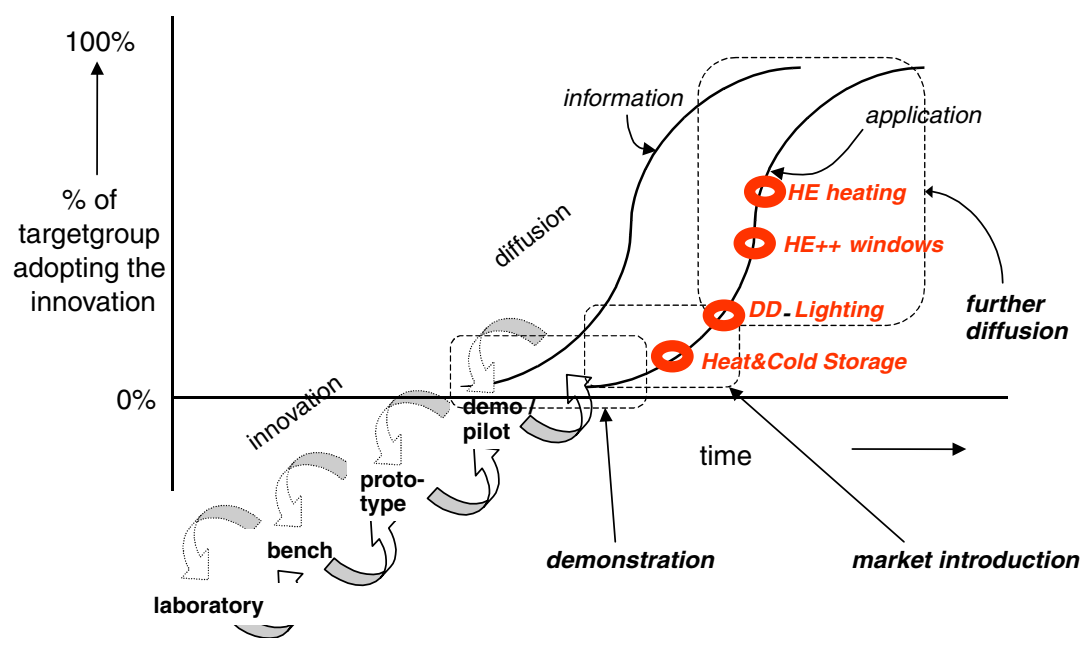

Fig. 2. Degrees of adoption of some energy-innovations.

(f) The intended level of EPS is determined in explicit discussion.

(g) Standardized procedures for selecting and assessing technologies and appliances are applied.

(h) The final choice of the level of EPS is a management decision.

(i) Information supplied by third parties is frequently used.

(j) Those appliances not included in the EPS calculation method (like elevators or kitchen equipment) are, nevertheless, all considered.

(k) Finally, implications for energy performance are also checked for changes in project specification during the tendering and construction phases.

In the following section, we report on how we applied this model to answer our central research question.

\section{Operationalizing the model in the field of $\mathbf{E}$ - innovations for office buildings}

Developers of a new office must make many decisions about possible application of a great number of technological innovations. Research into decision-making processes during the design and construction of new office buildings allows us to see how a wide range of explanatory variables influence the final decision to adopt or not to adopt innovations. We selected four of the most relevant innovations included within the system of EPS calculation. The selection was based on existing data on the proportion of the target group adopting various measures for reducing energy-use in offices (PRC Bouwcentrum, 2003) (Fig. 2). These innovations were (1) daylight dependent lighting systems (DD lighting) that allow up to $5 \%$ energy reduction of the total energy-use of a building, (2) high-efficiency heating systems (HE heating) that allow up to $4 \%$ energy reduction, (3) highly efficient insulated window glass (HE windows) that allow up to $9 \%$ energy reduction, and (4) underground heat and cold storage (H\&CS) that allows up to $20 \%$ energy reduction) (Novem, 2000a, b).

For this study, we translated the model in Fig. 1 to this field of application. This involved three activities. Firstly, all relevant policies, relevant authorities, but also players active in office building construction (suppliers, business associations, information centers, etc.) had to be identified. Secondly, operationalization of the model was needed in terms of plausible causal paths. Thirdly, to empirically determine, with multiple regression techniques, the relative importance of the various variables, we operationalized all explanatory variables as interval variables. This brought us to translate the model in Fig. 1 into the explanatory model as shown in Fig. $3 .^{4}$

The dependent variable is the actual adoption of a specific innovation in the building project, and the model aims to explain the dependent variable at two levels. At the first level, explanation is divided over two independent variables: (1) the project specific assessment of the innovation (the sum of the potential adopter's judgements on a specific list of criteria and his/her weighting of these criteria) and (2) the nature of the decisionmaking process (to what extent can it be characterized as a rational-synoptic process).

At the second level, the model explains either the nature of the decision-making process or the project specific assessment. We assume that the extent to which the nature of the decision-making process can be characterized as a rational-synoptic process depends on four factors. One, a serious occasion to innovate arises, either endogenous or exogenous. Here we may see

\footnotetext{
${ }^{4}$ In Fig. $3 \mathrm{E}=$ energy; $\mathrm{SB}=$ sustainable building; E\&E policyenergy and environmental policy; Gvt. = government.
} 


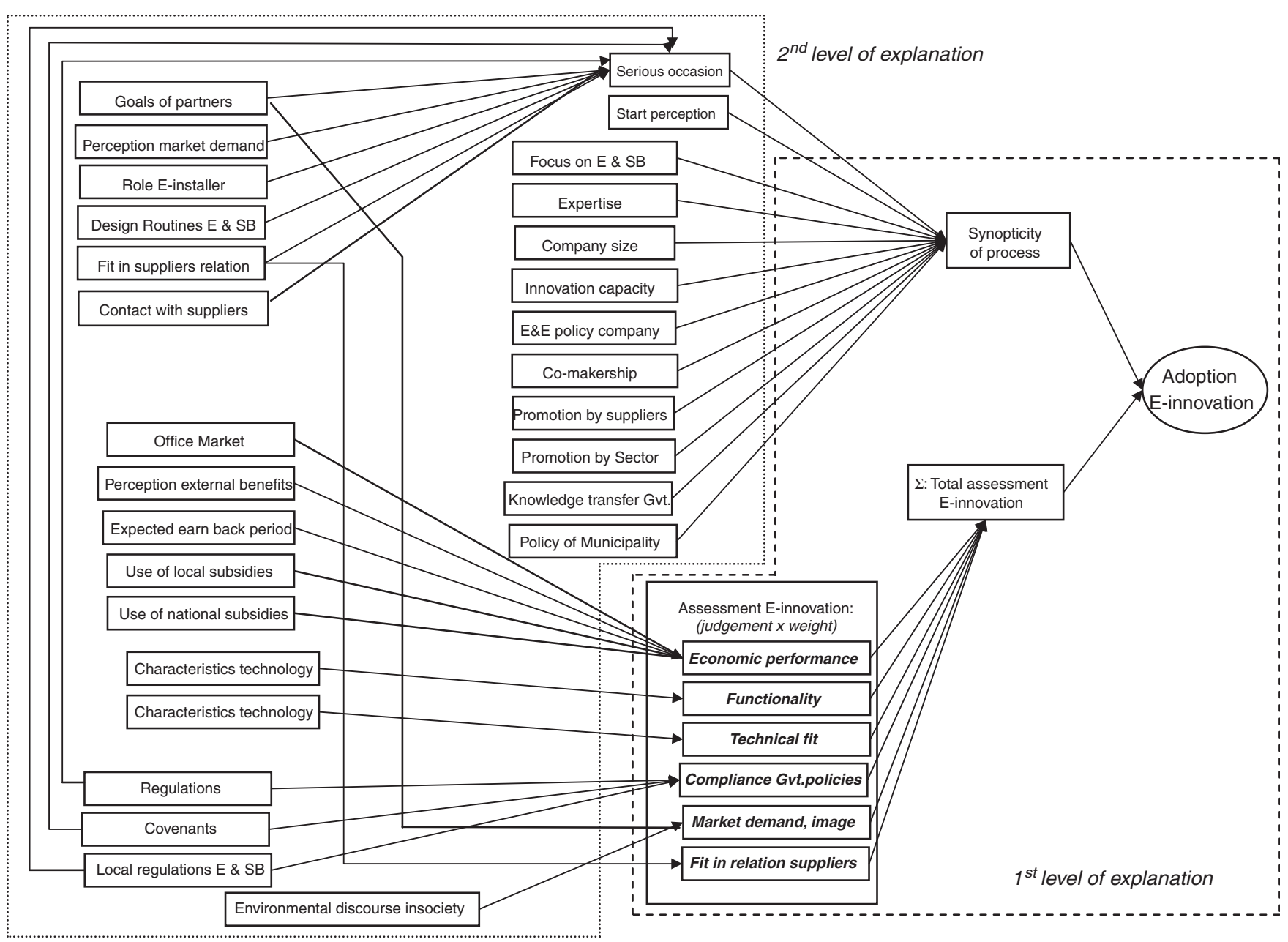

Fig. 3. Translated model for explaining adoption of E-innovations in new office-buildings.

influences of policy makers, clients or other actors in market or society. Two, the potential adopter's perception of the suitability of an innovation prior to the start of project development. Three, external influence coming from information transfer centres, advice agencies and suppliers. And four, characteristics of the project developing company (size, expertise, and use of environmental management systems).

Similarly, at the second level, the model explains the assessments made by potential adopters. For each assessment criterion, we identified explanatory variables including economic conditions and characteristics of the innovations. These variables explain either the judgements or the weights attained by these criteria.

\section{Methods}

We selected projects from a database developed in another study covering all construction permits in 15 municipalities, during the period 1 January 2000 to 1 August 2002 (PRC Bouwcentrum, 2003). In this period the required EPS level in the Netherlands was stable at 1.6. ${ }^{5}$ This database gave us information on how often the four innovations (DD lighting, HE heating, HE windows and H\&CS) and the EPS were adopted, as stated in the construction permits. It also provided us with the proportions of the target group that adopted the four innovations. Using this variance in adoption rates is helpful in understanding the relative importance of the explanations in the model.

The database provided us with data on 35 construction projects, the smallest having a floor size of at least $1000 \mathrm{~m}^{2}$. The projects together represent a surface of $370,000 \mathrm{~m}^{2}$, representing about $9 \%$ of the total floor size of office construction in the Netherlands in that period. Variances in floor size is displayed in Fig. 4, showing that $50 \%$ of the projects have a floor size of $>10,000 \mathrm{~m}^{2}, 12 \%$ between 5000 and $10,000 \mathrm{~m}^{2}$, whereas $38 \%$ has a size $<5000 \mathrm{~m}^{2}$.

\footnotetext{
${ }^{5}$ The EPS for office building started at the level 1.9 in 1995, was sharpened to 1.6 in 2000 and again sharpened to 1.5 in 2003.
} 
Comparing the variance in EPS levels in the PRC Bouwcentrum database cases with the variance in EPS levels in our cases revealed no sgnificant differences between the two data sets. Therefore we consider the data to be representative for construction projects larger than $1000 \mathrm{~m}^{2}$ during this period.

Closed questions were used for interviewing the project leaders (the potential adopters). Additional information was collected from municipal authorities and, when necessary, from experts advising the project developer on energy issues. In operationalizing the variables in Fig. 3, we either used 5-point scales or we combined information into indexes.

We used multiple regression techniques to determine the relative degree and in what relative proportions the model variables explain the adoption of E-innovations. At the first level of explanation we treated the factual adoption of an innovation as dependent variable and the variables representing either the process of decision making or the assessment of the innovation as

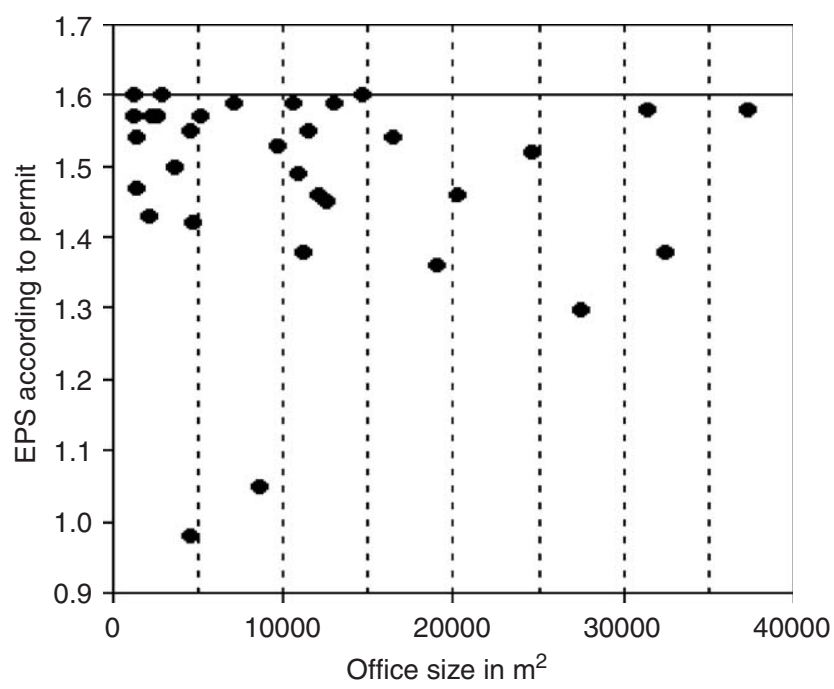

Fig. 4. EPS and office size in research cases. independent variables. Here we used the ENTER method, as we are dealing with theory-based models.

The explanatory power of the model is expressed by the $R^{2}$. This number expresses the total percentage of variance in the dependent variable that is explained by the independent variables in the model. In other words, to what degree do the process aspects and assessment criteria in the model explain adoption. We consider an $R^{2}=0.30$ (30\% explained by the model) as indicating a good result (Allison, 1999). In our discussions, we also display the $\beta$ values for each independent variable in the models. The larger the $\beta$ value, the more the level of adoption is explained by this variable. We also show the levels of significance, and set the minimum acceptable level to be $p<0.10$.

\section{Results and discussion}

\subsection{Proportion of target group adopting the four innovations}

We found that the four innovations were adopted by various proportions of the total target group as follows: $69 \%$ adopted high-efficiency windows, 50\% HE heating, 49\% DD lighting, and $21 \%$ adopted Heat and Cold Storage (H\&CS) (Fig. 5). Furthermore, if an option was not adopted, it was, in most cases, not considered at all (Fig. 5). We interpret this to be due to either lack of knowledge and experience, or that these options were not required for attaining the EPS.

We also found a common perception in the field to be that H\&CS only makes sense for offices larger than $15,000-20,000 \mathrm{~m}^{2}$. This, despite information supplied by experts to the potential adopters suggesting that $\mathrm{H} \& \mathrm{CS}$ is very effective in offices of $1500 \mathrm{~m}^{2}$ or larger.

We found a large variance of EPS levels as reported in construction permits (Figs. 6 and 7). More than 60\% had a value between 1.5 and 1.6, close to the compulsory

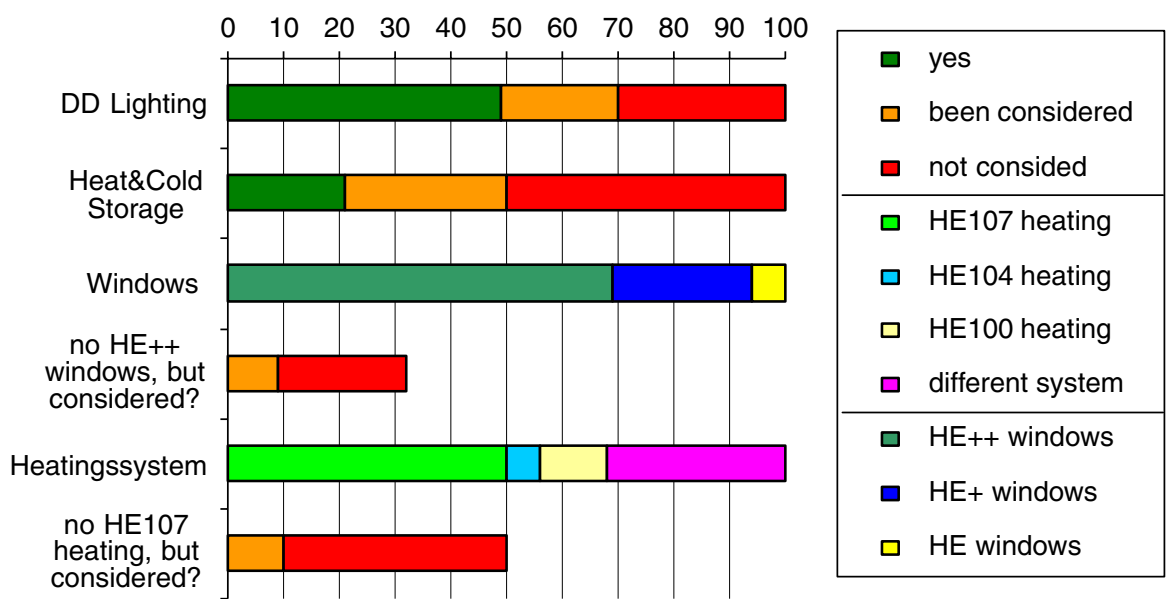

Fig. 5. Adoption levels. 


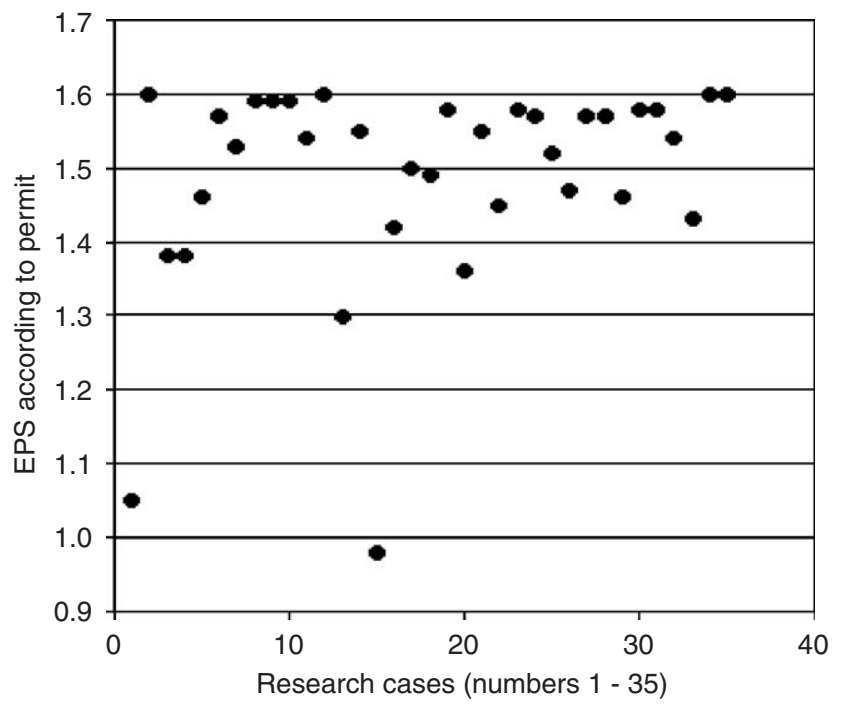

Fig. 6. Variance in EPS levels in research cases.

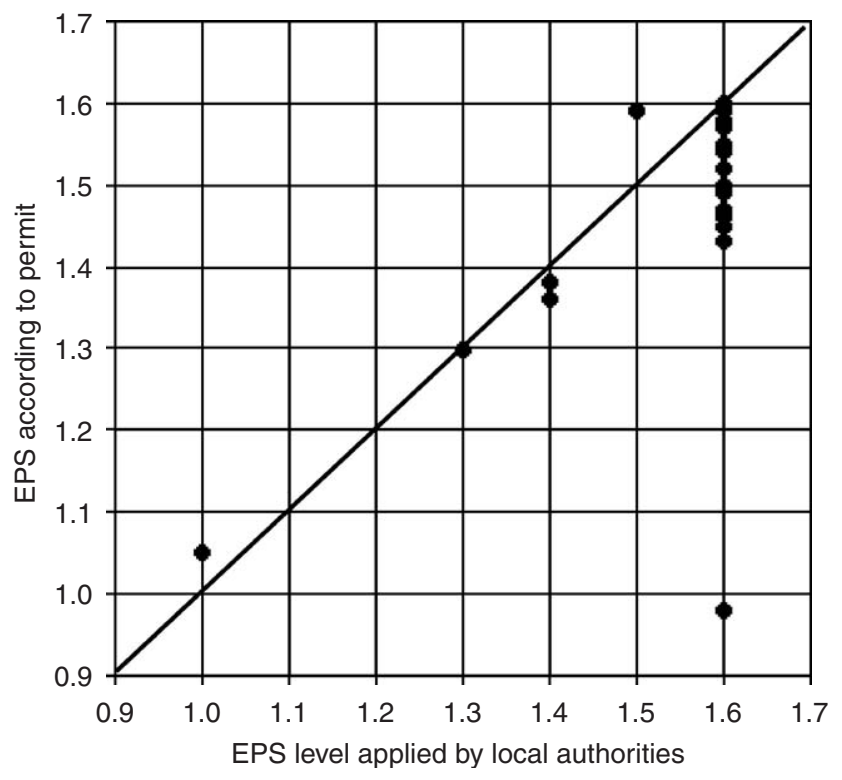

Fig. 7. Local EPS levels and EPS levels in permits.

level. Yet, $23 \%$ had values ranging from 1.5 to 1.4 and the remaining $17 \%$ had EPS levels even lower than 1.4, clearly running ahead of legal standards. In some cases this could be explained by local authorities applying more strict standards than the national standard.

\subsection{Assessments of the four innovations}

To measure the potential adopters' assessments of the innovations, we presented them with seven assessment criteria, reflecting the various explanation variables in our model. They were asked to give answers to statements such as 'this innovation is economically attractive in the case of our construction project'. We also asked them to indicate the 'weight' they attributed to each assessment criterion in making decisions for their project on a scale of ' 0 ' (no weight) to ' 10 ' (maximum weight). We gathered data for each of the four innovations, as illustrated by DD Lighting in Figs. 8 and 9.

The proportion of respondents agreeing with the statements appears at the left side of the ' 0 '-line, and the proportion of respondents disagreeing with the statements appears at the right ${ }^{6}$. In this case, DD Lighting was clearly assessed very positively with respect to being functional and simple in use $(72 \%$ positive) and technically easy to fit-in $(77 \%$ positive). Negative assessments concern market demand (54\% disagreed) and supplier support $(75 \%$ disagreed). Note that we found a large variance in the assessment of economic attractiveness.

We calculated weighted assessment scores by multiplying the assessment score by the weight score. The overall assessment of a specific innovation was then calculated as the sum of these seven weighted assessment scores. In theory, then, this overall assessment can vary from -210 to +210 . Fig. 9 shows the variance of these overall assessments for DD Lighting. All four innovations received more positive than negative overall assessments. DD Lighting and H\&CS received the largest number of negative outcomes.

The value and direction (positive or negative) of the overall assessment may give an explanation for the proportion of the target group adopting an innovation, and we assumed high positive overall assessment scores would correlate with adoption. Our test of this assumption is reported in Section 5.4.

\subsection{The nature of decision making}

In addition to assessments, our model proposes the nature of the decision-making process as a dominant explanation for adoption. In Section 2, we stated that a conscious weighing of pros and cons will only occur if potential adopters have a serious occasion for deviating from standard modes of working and if their initial perception of an innovation is not negative.

In Fig. 10 we show to what extent various conceivable exogenous and endogenous occasions for considering energy efficient designs were relevant in the eyes of the potential adopters. 'Being necessary to comply with EPS standard' (82\%) and 'requests of final owner or user' $(52 \%)$ were the main exogenous occasions. Looking at endogenous occasions, 'gaining experience with innovation' and 'we often go beyond legal requirements' were

\footnotetext{
${ }^{6}$ Responses having a neutral opinion or indicating lack of information are represented with the value ' 0 ', not being displayed in the figure. This explains that the left and the right bars do not sum up to $100 \%$.
} 


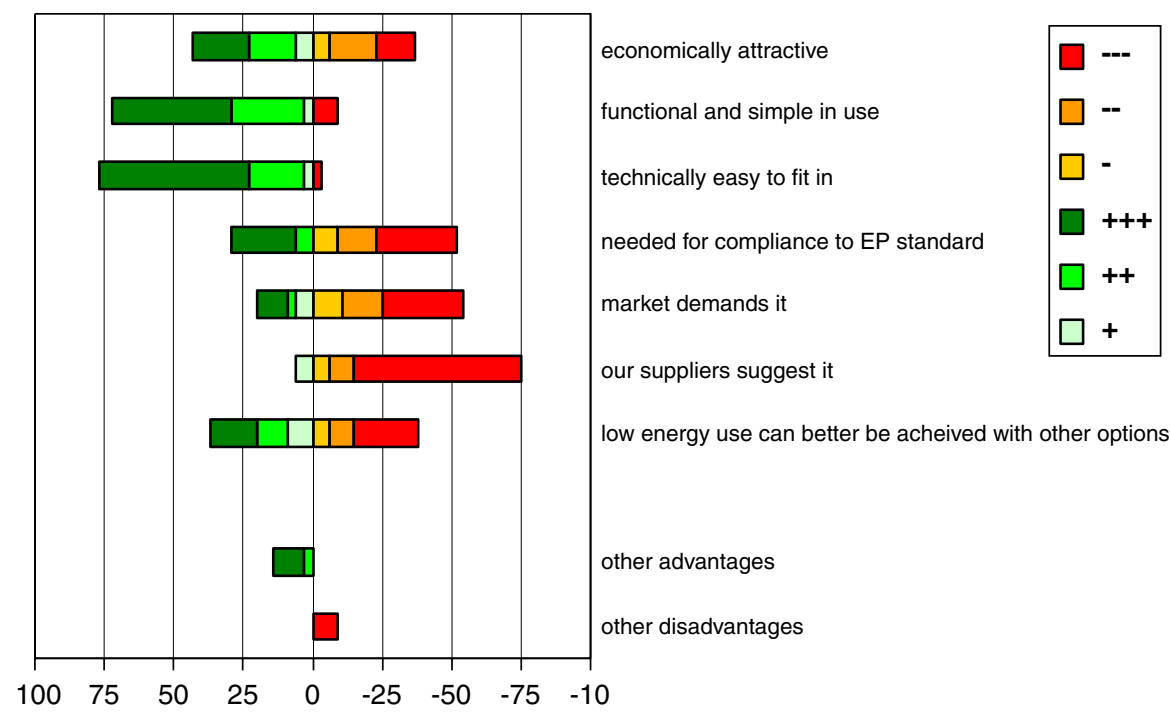

Fig. 8. Assessment of DD Lighting (\% respondents).

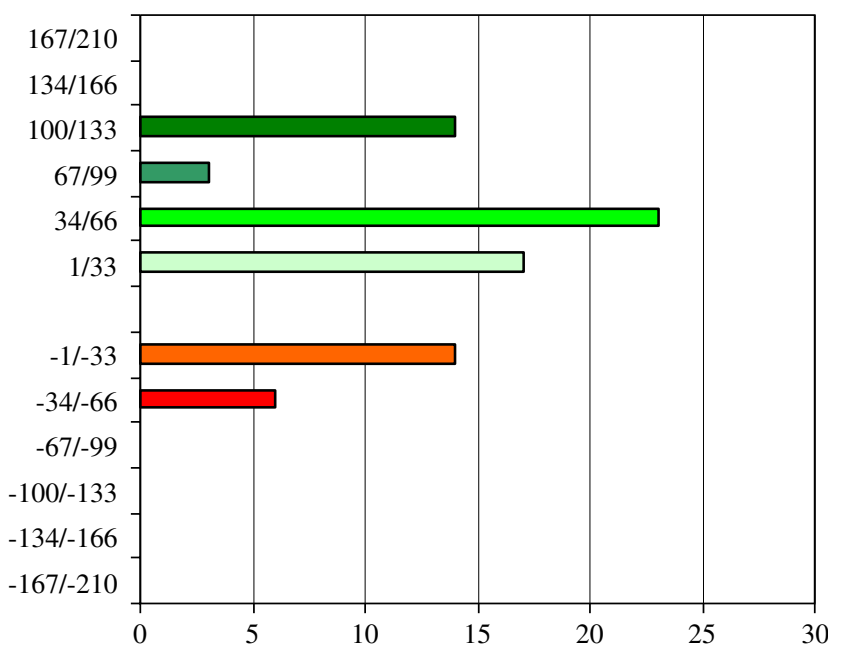

Fig. 9. Total Assessment Scores of DD Lighting (\% respondents).

claimed to be an occasion for considering energy efficient designs in only small numbers of projects. We used the answers to this question to construct an index variable summing the scores for each respondent, giving total scores ranging between 0 and 48. Equally dividing the outcomes in four categories, we found $20 \%$ of the cases in the lowest category $(0-12$, represent 'hardly any occasion'), $54 \%$ in the second category (13-24), another $20 \%$ in the third category (25-36) and only $6 \%$ in the highest category (37-48).

The potential adopter's initial perceptions of the Einnovations were, in a vast majority, positive. From this we conclude that eventual negative initial perceptions did not prevent adoption of these four E-innovations.

In Section 2 we distinguished between 11 ideal process aspects, reflecting the degree of rational-synoptic decision making. Fig. 11 shows our data from the 35 projects we analyzed. The first bar tells us that $86 \%$ of the potential adopters claimed that, right from the start, ideas about the level of energy performance were expressed to project partners. Although this says nothing about their ambitions, other data showed that of these potential adopters, $74 \%$ actually had ambitions in the field of sustainable and/or low-energy building. This was the most positive process aspect.

We found a considerable variance in the answers. For most decision-making aspects, about half of the projects did not mirror the 11 process aspects, expressing the rational-synoptic decision making ideal, as discussed in Section 2. With respect to choices on energy-related subjects in those cases, only a few options were explored, stakeholders were not involved in designing (49\%), EPS levels were not discussed $(66 \%)$ and in more than half of the cases management was not involved in assessing options. Procedures for selecting and assessing relevant energy-related options were used only by a minority of potential adopters $(29 \%)$.

In Section 5.4, we present our analysis of the correlation between these variances in the modes of decision making and the actual adoption of E-innovations. In this analysis we ignored items 1 and 7 in Fig. 11, because they are ambiguous, and items 9 and 10 , because they were relevant only after the moment of decision making. In addition, aspects $3-5$ in Fig. 11 were rather closely related; multiple regression showed high levels of interdependency between these three aspects. For our further analysis, we used the aspect correlating the strongest with our dependent variable, adoption.

\subsection{First-level analysis and discussion: assessment vs. decision-making process}

We statistically determined the relative explanatory power of the two first-level competing explanations: the 


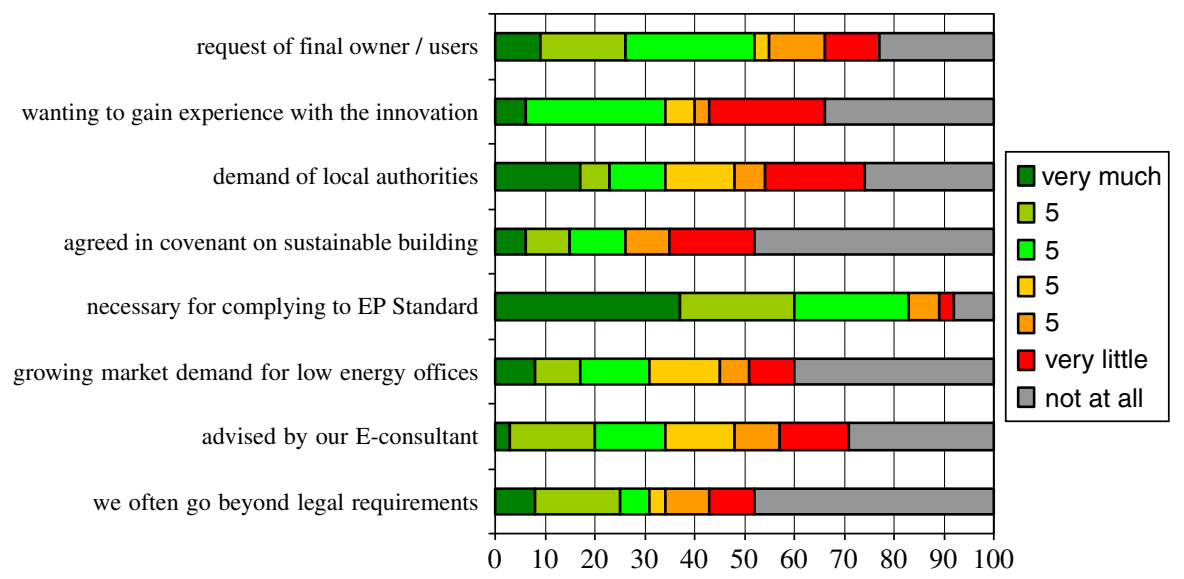

Fig. 10. Serious occasions for paying attention to E-innovations (\% respondents).

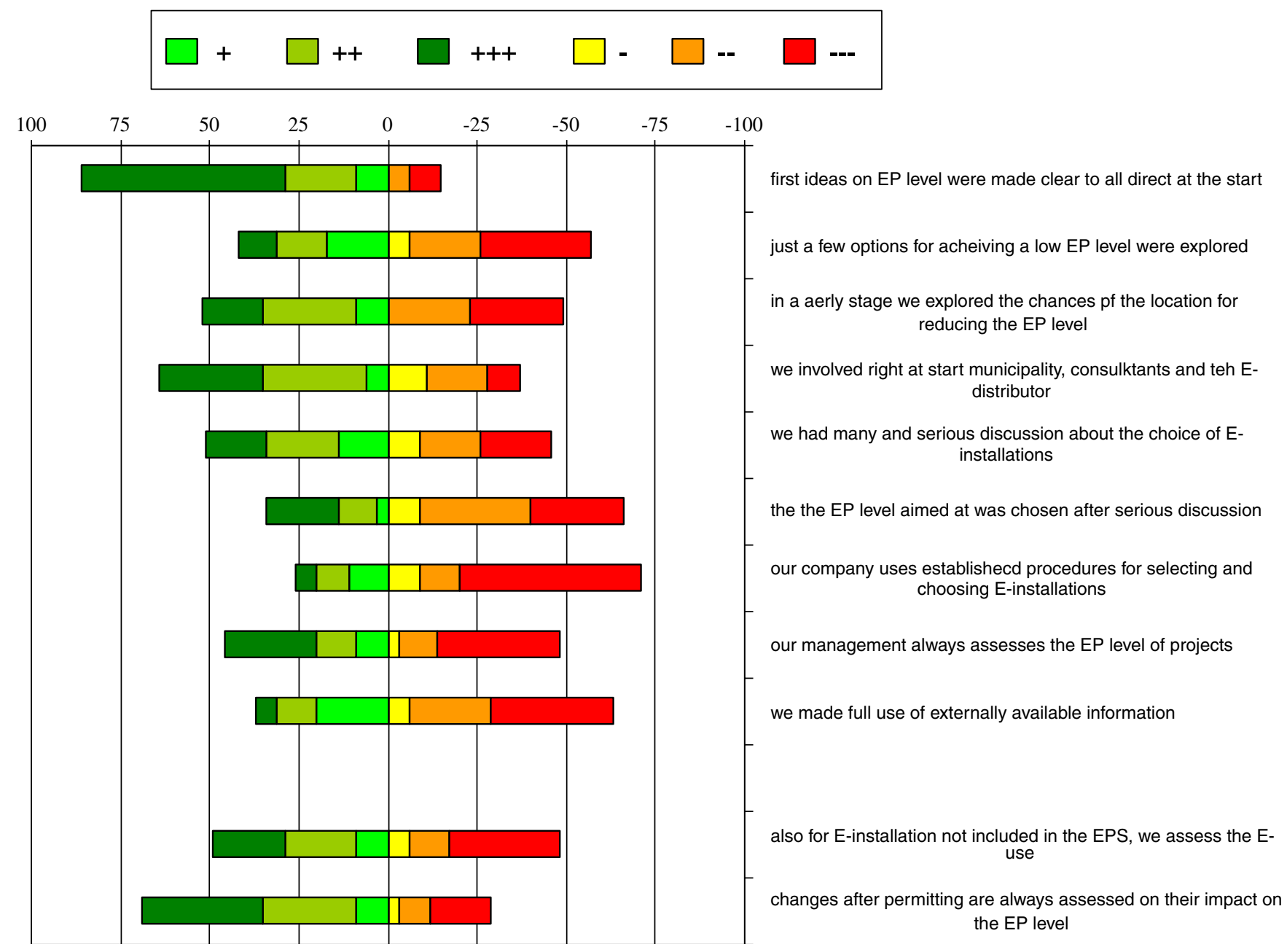

Fig. 11. Characteristics of the decision making process (\% respondents).

assessments versus the nature of decision making. Table 1 presents the results of our multiple regression analysis for each E-innovation separately.

The models for DD Lighting and for H\&CS show very high levels of explanation $(52 \%$ and $76 \%$ of the variance explained by the independent variables!). We also see significant $\beta$-values for several assessment criteria and process aspects.

For DD Lighting the assessment of the economic attractiveness and the process aspects 'explicit 
Table 1

Adoption explained by process aspects and assessment criteria

\begin{tabular}{|c|c|c|c|c|}
\hline $\begin{array}{l}\text { Model: } \\
R^{2}\end{array}$ & $\begin{array}{l}\text { DD Lighting } \\
0.522(0.000)\end{array}$ & $\begin{array}{l}\text { H\&CS } \\
0.760(0.000)\end{array}$ & $\begin{array}{l}\text { HE windows } \\
0.195(0.031)\end{array}$ & $\begin{array}{l}\text { HE heating } \\
\times\end{array}$ \\
\hline$\beta$ few options explored & $x$ & $x$ & $x$ & $\times$ \\
\hline$\beta$ opportunities location explored & $x$ & $x$ & $x$ & $x$ \\
\hline$\beta$ stakeholders involved from start & $x$ & $x$ & $x$ & $\times$ \\
\hline$\beta$ choices E-innovations discussed & $x$ & $x$ & $\times$ & $x$ \\
\hline$\beta$ EPS level discussed & $0.353^{* *}$ & 0.005 & 0.037 & $x$ \\
\hline$\beta$ management assesses EPS level & $-0.305^{* *}$ & 0.168 & $\times$ & $x$ \\
\hline$\beta$ full use of external information & $\times$ & $-0.182^{*}$ & $x$ & $x$ \\
\hline$\beta$ assessment economic & $0.386^{* *}$ & $0.487 * *$ & $x$ & $x$ \\
\hline$\beta$ assessment functionality & $\times$ & $\times$ & $x$ & $x$ \\
\hline$\beta$ assessment technical fit & $x$ & $-0.434 * *$ & $\times$ & $x$ \\
\hline$\beta$ assessment required for EPS & $x$ & $0.382 * *$ & $0.421^{* *}$ & $x$ \\
\hline$\beta$ assessment market demand & $x$ & $\times$ & $\times$ & $x$ \\
\hline$\beta$ assessment supplier's suggestion & $x$ & $-0.300 * *$ & $x$ & $x$ \\
\hline$\beta$ assessment: other & $x$ & $\times$ & $x$ & $x$ \\
\hline
\end{tabular}

Second row: $R^{2}$ scores (significance level between brackets).

$x$ : no significant correlation found.

$*$ :significant at $90 \%$.

$* *$ :significant at $95 \%$.

discussions on the EPS level' and 'management assesses EPS level' were the most relevant explanations (note that the correlation between 'management assesses EPS level' and 'adoption' was negative!).

In the case of H\&CS four assessment criteria and one process aspect were significant explanatory variables for the level of adoption.

The multiple regression models did not show a strong explanatory power in the case of HE windows (explaining $19 \%$ ) and not at all for HE heating. We see this as a very remarkable empirical outcome: neither the assessments, nor the nature of decision making explanted the adoption behavior! At the same time, these two Einnovations had the highest level of adoption (see Fig. 5). Apparently our model explained 'young' innovations, but not widely accepted innovations. One explanation for this is that adopting a widely accepted innovation may already have become a routine activity.

We tested this assumption as follows. One of the questions in our questionnaire asked potential adopters "whether specific options were used as a standard procedure'. We assume, here, that standard-adoptions of innovations will not correlate highly with the process aspects expressing rational-synoptic decision making. Furthermore, assessments of standard-adoptions will, presumably, be overwhelmingly positive. Such unanimity strongly reduces the explanatory power of any model.

Table 2 illustrates that adding the 'routine application' variable makes sense for these two E-innovations. The model now explains $33 \%$ of the variance in adopting HE windows. The model for HE heating explains only $10 \%$ or the variance, with 'routine application' as the only relevant explanation.
Table 2

Adoption explained by process aspects, assessment criteria and standard routines

\begin{tabular}{lll}
\hline Model: & HE windows & HE heating \\
$R^{2}$ & $0.331(0.005)$ & $0.100(0.064)$ \\
\hline$\beta$ few options explored & $\times$ & $\times$ \\
$\beta$ opportunities location explored & $\times$ & $\times$ \\
$\beta$ stakeholders involved from start & $\times$ & $\times$ \\
$\beta$ choices E-innovations discussed & $\times$ & $\times$ \\
$\beta$ EPS level discussed & -0.003 & $\times$ \\
$\beta$ management assesses EPC & $\times$ & $\times$ \\
$\beta$ full use of external information & $\times$ & $\times$ \\
$\beta$ standard routines & $0.407^{* *}$ & $0.316^{*}$ \\
$\beta$ assessment economic & $\times$ & $\times$ \\
$\beta$ assessment functional & $\times$ & $\times$ \\
$\beta$ assessment technical & $\times$ & $\times$ \\
$\beta$ assessment EPC & 0.272 & $\times$ \\
$\beta$ assessment market demand & $\times$ & $\times$ \\
$\beta$ assessment supplier's suggestion & $\times$ & $\times$ \\
$\beta$ assessment: other & $\times$ & $\times$ \\
\hline
\end{tabular}

Second row: $R^{2}$ scores (significance level between brackets).

$x$ : no correlations found.

*: significant at $90 \%$.

$* *$ : significant at $95 \%$.

\subsection{Second-level analysis and discussion: explaining assessment criteria and decision-making aspects}

To explain the project specific assessment and the nature of the decision-making process, we considered only those variables of assessment criteria and process aspects that were found to be statistically relevant explanations for adoption (Table 1). 


\subsubsection{Explaining significant assessments}

We found economic assessments to be relevant for the two 'young' E-innovations. As possible second-level explanations, we tested: the development in the office building market, the growth perspectives of the developing companies, the expected returns on investments, the acceptation of eventual extra investments, and possibly received subsidies.

Although the market for new office buildings in the Netherlands completely collapsed after 2003, during the research period, potential adopters were still very optimistic; $69 \%$ of them did not expect a surplus of new offices on the market during the period of building their new office. Regarding the growth perspective of the developing companies, half of the potential adopters had no clear idea or did not want to give an answer, whereas $37 \%$ had positive expectations and $6 \%$ negative expectations.

The variable expected return on investment is a different story. Potential adopters often stated that they do not know this, and that it is not really an important consideration. They state that it is used as an argument for marketing, but that it does not usually really play a role, as the investor (the developer) is not the one benefiting from cost-saving low-energy appliances. Because of non-processable answers we could not include this variable in our second-level analysis. However, we also collected qualitative judgements on the acceptability of extra investment costs for the various E-innovations. These were included in the analysis.

As a final explanation of economic assessment, we determined what proportion of potential adopters had applied for subsidies. These proportions were: for DD Lighting, $14 \%$ of the projects; for $\mathrm{H} \& \mathrm{CS}, 20 \%$; for $\mathrm{HE}$ windows, $20 \%$; and for HE heating, $11 \%$.

We analyzed these second-level explanations with multiple regression analysis with 'weighted economic assessment' as dependent variable (Table 3). In the case of DD Lighting, the 'acceptability of extra investments' and 'use of subsidies' significantly explain $53 \%$ of the total explained variance in 'weighted economic assessment'. We found that for H\&CS, the 'use of subsidies' accounted for $41 \%$. Again, for the mature E-innovations, the model did not produce significant outcomes.

The perception of technical fit-in, the second assessment criterion addressed here, was found to be significant in the first level of explanation in the case of H\&CS. To explore this more in detail we used aspects of technological fit-in, taken from Rogers (1995). These aspects cover questions like whether the E-innovation is too complex for the installation supplier involved; whether it fits in the specific type of office they plan to build; whether it is easily available on the market; whether developers can choose between various competing suppliers; and whether the E-innovation fits within technical standards. For three of the four E-innovations the potential adopters perceived few problems in this sense. For H\&CS innovations, however, we found more diverse perceptions of the technical fit-in. However, we did not find a significant correlation between these aspects of fit-in and the 'weighted assessment' of technical fit-in.

Needed for compliance to EPS standard, the third assessment criterion addressed here, was significant in explaining the adoption of both $\mathrm{H} \& \mathrm{CS}$ and $\mathrm{HE}$ windows. As a second level of explanation, we tested the influence of the EPS instrument. Measuring the effect of a national standard is difficult in many countries, because regulations generally tend to result in one uniform level of compliance. In that case, regression analysis would not produce any useful result because the independent variable is constant. But, in the Netherlands, municipalities do have a certain level of policy discretion: they can and do impose stringent standards (Fig. 7). Table 4 shows the results of the regression analysis using the local EPS level as explanation for the weighted assessments on the need for adopting the various E-innovations for compliance to the EPS. Again for the 'young' innovations we see significant correlations, especially strong for H\&CS. Here we see clear evidence of the effectiveness of the EPS instrument for enhancing adoption of innovations.

Our supplier suggests it, the fourth assessment criterion, deals with supplier relations. Innovation

Table 3

Weighed economic assessment explained by various variables

\begin{tabular}{llll}
\hline Model: & DD Lighting & H\&CS & $\begin{array}{l}\text { HE heating } \\
0.409(0.097)\end{array}$ \\
$R^{2}$ & $0.533(0.023)$ & $0.253(0.359)$ \\
\hline$\beta$ demand on office market & -0.256 & 0.115 & 0.257 \\
$\beta$ acceptability of extra investment costs & $0.504 * *$ & 0.155 & 0.133 \\
$\beta$ expected growth company & 0.323 & 0.246 & 0.157 \\
$\beta$ use of subsidies & $0.667 * *$ & $0.574^{* *}$ & 0.1739 \\
\hline
\end{tabular}

Second row: $R^{2}$ scores (significance level between brackets).

$x$ : no correlations found.

*: significant at $90 \%$.

$* *$ : significant at $95 \%$. 
Table 4

Weighed assessment of 'comply to EPS' explained by EPS level municipality

\begin{tabular}{lllll}
\hline Model: & DD lighting & H\&CS & HE windows & HE heating \\
\hline$R^{2}$ & $0.168(0.022)$ & $0.444(0.000)$ & $0.030(0.353)$ & $0.034(0.322)$ \\
\hline
\end{tabular}

Second row: $R^{2}$ scores (significance level between brackets).

studies regularly stress the important role of intermediaries like suppliers of equipment, who have to "pass through' the innovation (Brezet, 1994). This assessment criterion was significant in the first-level analysis for the case of H\&CS. In our second-level analysis we investigated the role of suppliers: whether potential adopters work with regular suppliers and what attitudes their regular suppliers have to the E-innovations. Remarkably, between $14 \%$ and $27 \%$ of the potential adopters (differing per innovation) did not know whether their suppliers have any experience with the various innovations. Also, between $17 \%$ and $37 \%$ had no clue about their suppliers' attitudes towards these innovations. The interviews revealed that for energy issues contacts with suppliers often are very indirect, using subcontractors. Given this information it was not surprising that second-level explanatory variables covering the relation with suppliers did not significantly correlate with those weighted assessment criterion.

\subsubsection{Explaining significant aspects of the nature of the decision-making process}

In the model (Fig. 3), three groups of independent variables may explain the level of synopticity of the decision-making process. We carried out multiple regression analysis for these three groups of variables.

First, we look at relevant serious occasions for considering the E-innovations and the developer's initial perceptions of these innovations. In Section 5 we discussed various occasions and constructed an index for this variable. This allowed us to test the hypotheses that the nature of the decision-making process depends on the perception of endogenous and exogenous occasions for considering new solutions in the field of energy-use in office designs. Our regression analysis resulted in a significant correlation: the 'sum of occasions' explains $19 \%$ of the level of synoptic rational decision making $\left(R^{2}=0.191, p=0.009\right)$. Looking at the various occasions separately, our analysis revealed that the occasion 'we often go beyond legal requirements' (see Fig. 10) was the most relevant occasion $\left(R^{2}=0.233\right.$, $p=0.003$ ). In other words, frontrunner companies more thoroughly prepared their decisions.

We explored the possible occasions in more detail, by looking at possible impulses from outside the company (government, business partners, and advisers) and inside the company (design procedures). We found that an
Table 5

'Serious occasion' explained by various variables

Model:

$R^{2}$

$0.338(0.004)$

$\beta$ role E-adviser

$\beta$ working with design routines

$\beta$ EPS level municipality

$\beta$ perception of market demand

$0.344 * *$

$\times$

$-0.523^{* *}$

$\times$

Second row: $R^{2}$ scores, (significance level between brackets).

$x$ : no correlations found.

$*$ : significant at $90 \%$.

$* *$ : significant at $95 \%$.

Table 6

'Having considered an option' explained by 'initial perception'

\begin{tabular}{lllll}
\hline Model: & DD lighting & H\&CS & HE windows & HE heating \\
\hline$R^{2}$ & $0.123(0.039)$ & $0.186(0.010)$ & $0.082(0.096)$ & $0.017(0.453)$ \\
\hline
\end{tabular}

Second row: $R^{2}$ scores (significance level between brackets).

active role of energy advisers and a higher local level-ofrequired-EPS together account for $34 \%$ of the variance in the 'serious occasion' score (Table 5).

In Section 5 we discussed potential adopters' initial perceptions of the E-innovations as possible barriers for considering innovations. Table 6 shows the analysis of the relationships between these two variables. In three of the four cases (DD lighting, H\&CS, HE windows), we found significant but rather weak correlations, so in these cases initial perceptions weakly influenced the actual consideration of these innovations.

After having discussed the role of occasions and initial perceptions we can now discuss various possible explanations for the level of synopticity in the decisionmaking process. In the model we included company characteristics (company policy on sustainable building, company size, expertise in the field of sustainable building and E-innovations, use of environmental management systems, innovation capacity and co-maker relationships) and external influences coming both from governments (others then already covered, like knowledge transfer and advises from local authorities) and market (promotion by suppliers).

\subsubsection{Company characteristics}

As a first characteristic we analyzed whether sustainable building was an element in the potential adopter's company policy. In our regression analyses, we used data on the relative importance attached to various possible office design goals.

The level of expertise was measured as the number of employed experts. In most cases no specialists in sustainable building or energy appliances were in-house, but often experts where consulted. 
The company size varied very strongly, $34 \%$ involving less then 10 employees and $40 \%$ employing between 20 and 250 people.

To measure innovation capacity we used reports on measuring innovation ability of firms (de Jong and Brouwer, 1999; de Jong et al., 2001). De Jong et al. have proposed a method using questions addressing the innovation culture, structure and policy within a company. We reduced this to seven statements in our questionnaire. Some results are that $86 \%$ of the developers state that they work with multidisciplinary teams; three-quarter of the companies said their designers are free to make their design choices and $95 \%$ stated that the designers are given a large degree of responsibility for their own products. Looking at the company policy, $45 \%$ of the respondents stated that the mission statement of the company also mentions the innovative capacities of the employees and no more than $43 \%$ stated that their company's policy also addresses the development of innovative offices. Where the results on the first statements seem to suggest high-level innovation capacities, the last few statements point in the opposite direction. Or, as sometimes stated in the interviews: 'we have both our feet on the ground' or 'we work on market-demand'. Operating on market demand is said not to imply neglect of innovations, but that adoption will only happen if the future user or owner explicitly demands this. For our analysis we used the sum of the outcomes on the seven statements.

As a fourth characteristic of companies we looked whether companies work according to the principles of environmental management systems (ISO, 1996; Heida and Hortensius et al., 1997; Sheldon, 1997; Kolk, 2000). Working with an environmental policy may be assumed to promote serious evaluation of design alternatives. The more far-reaching its environmental policy, the more likely the potential adopter will evaluate the pros and cons of the E-innovations under study. To measure this we constructed an index, applying scores to the various elements of an environmental management system, where having an ISO 14001 certificate results in the maximum score of 12 points. Only one of the respondents had this certificate. One-third of the companies had an environmental policy statement; and $23 \%$ of the firms had an environmental program. Also, one-third used procedures to deal with sustainable building issues and $46 \%$ claimed to work with energyrelated design procedures. Finally, $40 \%$ of the companies stated that developments in environmental polices and innovations are translated into new company policies.

In addition to these company characteristics, we looked at external influences. Firstly, active promotion by suppliers may be relevant for considering such innovations. We asked whether suppliers of E-innovation had contacted them. In a small $26 \%$ of the cases this had happened. Secondly, we looked at the use of external sources of information. In this case we identified 14 different sources of market and governmental information supply about E-innovation in new office construction. For each, we analyzed whether these sources were known, used and well appreciated. The most well-known and appreciated information sources were two government agencies. However most of the information products were used by approximately onethird of the developers. For our analysis we summed the results into an index score. Thirdly, an active role of local authorities may also contribute to rational-synoptic decision making. If local officials are closely involved with design teams in discussing the use of sustainable building and low-energy applications, rational-synoptic decision making will be promoted. We asked about the intensity of consultations with municipal officials. In $70 \%$ of the cases the intensity was zero! Construction permits for office buildings were dealt with, without discussion of these topics. This is to some extent surprising, because, in the field of construction of dwellings, intensive consultation does take place in many municipalities (Waals and Vermeulen, 2000). We contacted all municipalities involved and confirmed this finding. Although active consultation occurs in the case of building new dwellings, municipalities are reluctant to exercise pressure in the case of utility buildings. Apart from a lack of administrative capacity, a fear of losing out to competition on the market for offices (and jobs) is a frequent explanation.

We tested the various explanations for the nature of the decision-making process with multiple regression analysis. Table 7 shows that only three of these possible explanations really mattered. 'Having an environmental management system', 'supplier promotion' and 'company size' were the only three significant explanations, accounting for $66 \%$ of the variance in synopticity of the process. In other words, potential adopters tended to more thoroughly evaluate alternatives if they work according to environmental management system principles, if they are large and if they have been contacted by suppliers.

Table 7

Synopticity decision-making process explained by various variables

\begin{tabular}{ll}
\hline $\begin{array}{l}\text { Model } \\
R^{2}\end{array}$ & $0.658(0.030)$ \\
\hline$\beta$ environmental management system & $0.635^{* *}$ \\
$\beta$ promoted by E-installer & $0.332^{* *}$ \\
$\beta$ company size project developer & $0.306^{* *}$ \\
\hline
\end{tabular}

Second row: $R^{2}$ scores (significance level between brackets).

*: significant at $90 \%$.

$* *$ : significant at $95 \%$. 


\section{Conclusions and implications for policy}

In this article we presented and discussed the empirical results of our study to answer the question:

To what degree and in what relative proportions do variables representing the nature of decision-making, company characteristics, technology characteristics, economic characteristics, government policy, and influences from market and society explain potential adopters' decisions to adopt E-innovations in new office building construction?

We are now able to answer this question in such a way that the possible interrelatedness between various competing explanatory variables has been controlled. We used two levels of analysis. At the first level the decision to adopt an E-innovation was explained by variables representing either assessments of the innovation or the nature of the decision-making process. At the second level of analysis we used variables representing company characteristics, technology characteristics, economic characteristics, government policy and influences from market and society to explain the variations in the process variables and the assessment variables.

Looking at the first level of analysis for DD Lighting, the decision to adopt this innovation was roughly equally explained by three variables: the economic assessment $(\beta=0.386)$, the management involvement in assessing the EPS level $(\beta=0.353)$ and the appearance of serious discussions on the energy performance level in the project $(\beta=-0.305)$. Together, these three variables explain $52 \%$ of the variance in adoption decisions (Table 1). For H\&CS, the decision to adoption was explained by five variables: being one 'process' variable (full use of external information: $\beta=-0.182$ ) and four 'assessment' variables: the economic assessment $(\beta=0.487)$, the technical fit $(\beta=-0.434)$, being required for the EPS $(\beta=0.382)$ and supplier's suggestions $(\beta=-0.300)$. Together, these variables explain $76 \%$ of the variance in adoption of H\&CS (Table 1). In both cases, adding the variables of modes of decision-making processes produces higher levels of explanation then merely looking at weighted assessments of innovations.

An unexpected result of our study highlights the difference between these two 'young' (DD Lighting and $\mathrm{H} \& \mathrm{CS}$ ) and the other two 'mature' $\left(\mathrm{HE}^{++}\right.$windows and HE107 heating) innovations. The model generated very acceptable levels of explanation for 'young' innovations, but needed a minor adjustment for 'mature' innovations: adding a variable expressing the entrance of a stage of 'routine application'. Adopters deal with mature innovations in a, more or less, routine way, and give these innovations relatively little extra consideration. Potential adopters deal with young innovations much differently.
Our second level of analysis showed that company environmental and energy policy (does it have an environmental management system in operation?, $\beta=0.635)$ and suppliers' promotion $(\beta=0.332)$, the company size $(\beta=0.306)$ were the variables explaining the nature of the decision making process, the first being twice as strong as the other two. These three variables account for $66 \%$ of the variance in the decision-making process (see Table 7). This implies that indirect policies supporting the application of environmental management systems and supporting an active role of suppliers may be very effective in increasing diffusion of $\mathrm{E}$ innovations.

In explaining the assessments we found that the use of subsidies was the strongest explanation for the differences in the economic assessment of the 'young' innovations DD Lighting $(\beta=0.667$, model explaining $53 \%)$ and $\mathrm{H} \& \mathrm{CS}(\beta=0.574$, model explaining $41 \%$ ).

In the case of H\&CS one of the explanatory 'assessment' variables was 'being required for the EPS'. We found that variances in locally required EPS levels explain this assessment for $44 \%$ (Table 4). This same variable, expressing the most important policy instrument, also proved to be the main variable explaining whether developers felt a serious occasion for considering E-innovations $(\beta=-0.523$, model explaining $34 \%$ in Table 5). Both findings stress the effectiveness of this policy instrument, but we also saw that these effects are not traceable for the more mature E-innovations.

Given these results, we conclude that our two-level strategy of analysis has enabled us to identify the relative effectiveness of various policy-instruments used simultaneously in practice.

The second version of the model can very well be used to summarize the results. In Fig. 12 we have highlighted those causal relations that empirically have proved to be significant. ${ }^{7}$ We have indicated 'very strong causal relations' with extra thick arrows where we found, at least for one of the E-innovations, $|\beta|>0,50$ or $\left|R^{2}\right|>0,50$. 'Strong causal relations', indicated with a less thick line, represent significant correlations for at least one of the E-innovations where $|\beta|>0,30$ or $\left|R^{2}\right|>0$, 30. Where we found, in at least one case, $|\beta|<0,30$ or $\left|R^{2}\right|<0,30$ a striped line expresses a 'weak causal relation'. For all other predicted relations, which were not confirmed in this analysis, we use dotted lines. Some of the originally predicted explanatory variables are now printed in gray, indicating that we did not find this aspect in this study. This implies that we cannot judge their effects based on this study. In other

\footnotetext{
${ }^{7}$ In Fig. $12 \mathrm{E}=$ energy; $\mathrm{SB}=$ sustainable building; E\&E policyenergy and environmental policy; Gvt. = government.
} 


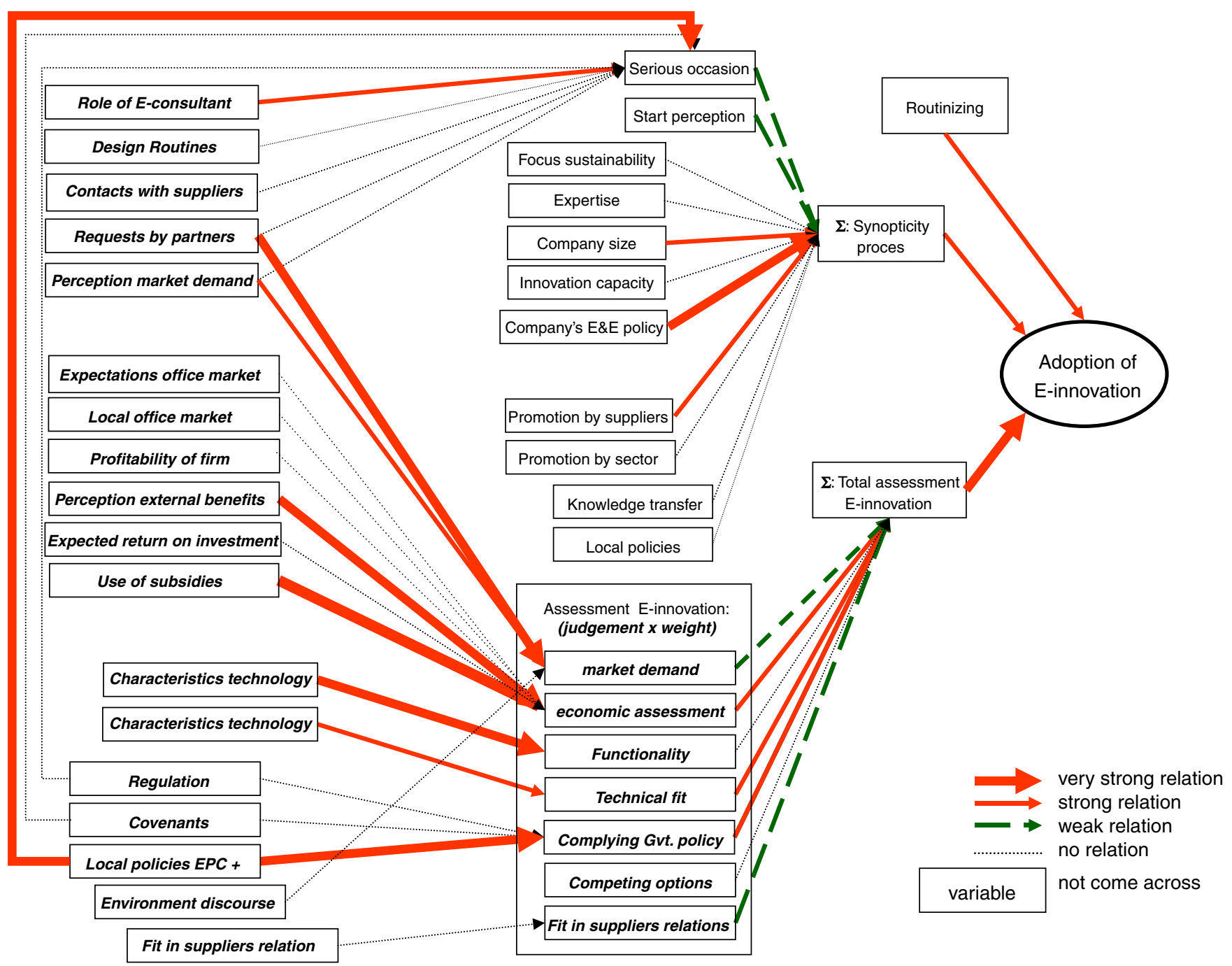

Fig. 12. Tested model for explaining diffusion of E-innovations office buildings.

situations, or by using another mode of operationalization, statements about these variables might very well be possible.

Expressed in this way, Fig. 12 serves as a basis for policy advice. The highlighted lines represent effective routes for influencing decisions of utility developers to adopt innovations. However, most but not all of these causal relationships represent factors that can be manipulated by policies (the size of a company, for instance).

Those proven relations are best taken as starting points for policy advice. The non-proven relations need closer inspection. Two situations may occur. Firstly, the predicting explanatory variable is found, in practice, to have considerable variance but does significantly correlate with the dependent variable in the model. In that case this variable does not offer any useful opportunity for policy making. But, secondly, the phenomenon described by the predicting explanatory variable does not occur in practice in this field or does not show any variance over the cases. In these situations, potential correlation cannot be statistically tested, and a judgment on its effect must be postponed. In that case no policy advice can be derived from this empirical study, but can, at most, be based on other evidence.

We saw that the economic assessment criterion was one of the significant variables in explaining adoption for two of the four E-innovations. But for the 'young' innovations (DD lighting and H\&CS) also other, nonfinancial criteria and process aspects turned out to be significant in explaining adoption. For the 'mature' innovations routine application was the main explanation, but here we must stress that this only makes sense given a positive evaluation of economic performance, functionality and technical fit-in these applications.

We should acknowledge that office developers, as the final responsible decision maker, are not well informed about the economic performance of new technologies. A more specific assessment is generally delegated to energy advisers, who confined to operate within the same 
restrictions of the developer (e.g. maximum investments or EPS level).

Looking at the role of government, we clearly see two of the policy instruments used by both the national and the local authorities in the Netherlands being effective. Intended effects of other instruments (like covenants and information supply) did not show up. On one hand, we could not verify that the use of information supplied by government agencies was effective. This is remarkable, being in contrast with the impact of suppliers' promotions that did prove to be effective. Governments might, therefore, better use this 'indirect' route for information supply.

On the other hand, the use of subsidies clearly effected the 'weighed economic assessment' of the 'young' innovations, thus affecting adoption rates. This is remarkable because we also saw only a small group of developers actually using these subsidies. The second and most effective instrument is the EPS; especially the application of various levels of Energy Performance in different cities strongly correlates with adoption levels. We also saw that the EPS affects decisions on the 'young' innovation better than for 'mature' innovations. Taking these findings together, we conclude that the instrument of Energy Performance Standards will, at best, be effective if it is regularly made more stringent and if it addresses more recently emerging appliances. This may be a very crucial empirical finding, given the current implementation of this instrument under way in all EU countries.

\section{References}

Allison, P.D., 1999. Multiple Regression: A Primer. Pine Forge Press, Thousand Oaks, CA, USA.

Anink, D., Boonstra, C., et al., 1996. Handbook of Sustainable Building: An Environmental Preference Method For Selection Of Materials For Use In Construction And Refurbishment. James and James, London.

Bekke, A. J. G. M., 1988. Besluitvorming in organisaties, het werk van J.P.Olsen. Bestuurskunde, hoofdfiguren en kernthema's. A. F. A. e. T. A. J. T. Korsten, Bestuurskunde, hoofdfiguren en kernthema's, Leiden, 1988.

Brezet, J. C., 1994. Van prototype tot standaard; De diffusie van energiebesparende technologie. Een onderzoek naar het diffusieproces van Hoog-Rendement CV-ketels in de particuliere huishoudelijke sector in Nederland over de periode 1981-1992. Rotterdam, Denhatex.

de Jong, J.P.J., Brouwer, E., 1999. Determinants of the Innovative Ability of SMEs - Literature Review. Zoetermeer, EIM/SEO. de Jong, J.P.J., Kemp, R., et al., 2001. Determinants of the Innovative Ability-An Empirical Test of a Causal Model. Zoetermeer, EIM.

Dieperink, C., Brand, I., et al., 2004. Diffusion of energy-saving innovations in industry and the built environment: Dutch studies as inputs for a more integrated analytical framework. Energy Policy 32 (6), 773-784.

Glasbergen, P., 1984. Visies op beleid sociaal-wetenschappelijke analyse van overheidsbeleid. Amsterdam, Kobra.

Haarman, H.R., Leeuwen, E.N.V., et al., 2000. Sustainable building policy in the Netherlands. Milieu Journal of Environmental Sciences 15 (2), 62-70.

Hal, A.V., Hulski, B., 1999. Sustainable Housing in Europe. Delft, Boom-Duijvestein.

Heida, J.F., Hortensius, D., et al., 1997. Werken met ISO 14000 (Working with ISO 14000). Delft, Nederlands Normalisatie Instistuut (NNI).

Hickson, D., et al., 1986. Top Decisions: Strategic Decision-making In Organizations. Oxford.

Hoppe, R., 1987. Trends in besluitvormingstheorie en ontwerpleer. Amsterdam.

ISO, 1996. ISO 14001:1996. ISO, Geneve.

Kickert, W.J.M., 1986. Overheidsplanning. Assen.

Kolk, A., 2000. Economics of Environmental Management. Pearson Education Ltd, Harlow.

Korsten, A.F.A., Toonen, T.A.J. (Eds.), 1988. Bestuurskunde, Hoofdfiguren en kernthema's. Leiden.

Lindblom, C.E., 1959. The science of muddling through. Public Administration Review 19, 79-88.

Lindblom, C.E., 1968. The Policy-Making Process. Prentice-Hall Inc., Englewood Cliffs, NJ.

Lindblom, C.E., 1977. Politics and Markets. Basic Books, Inc., New York.

Novem, 1999. Duurzaam bouwen monitoring. Resultaten Plannen van Aanpak 1995-1999. Den Haag, Ministerie van VROM.

Novem, 2000a. Energieprestaties van kantoorgebouwen: inspiratiebron voor duurzame investeringen. Utrecht, Novem.

Novem, 2000b. Energieprestaties van utiliteitsgebouwen: meer mogelijkheden door clustering van gebouwen. Utrecht, Novem.

Poel, B., Vries, G.D., et al., 2002. The Integrated Design Process In Practice: Demonstration Projects Evaluated. Arnhem, Damen Consultants, The Netherlands.

PRC Bouwcentrum, 2003. Energieprestaties van nieuwe kantoren op basis van vergunningaanvragen. Woerden, PRC Bouwcentrum.

Rogers, E.M., 1995. Diffusion of Innovations. The Free Press, New York.

Sheldon, C. (Ed.), 1997. ISO 14000 and Beyond: Environmental Managemnet Systems in the Real World. Greenleaf Publishing, Sheffield.

Vermeulen, W.J.V., Hovens, J., et al., 2004. Verklaring succes Einnovaties bij nieuwbouw van kantoren. Universiteit Utrecht, Copernicus Instituut, Utrecht.

Waals, J.F.M.v.d., Vermeulen, S.M.J., et al., 2000. Energiebesparing en stedelijke herstructurering, een beleidswetenschappelijke analyse. Utrecht, Nethur.

Waals, J.F.M.v.d., Vermeulen, W.J.V., 2000. Sustainable building: lessons for local policy processes, Milieu. Journal of Environmental Sciences 15 (2), 103-110. 